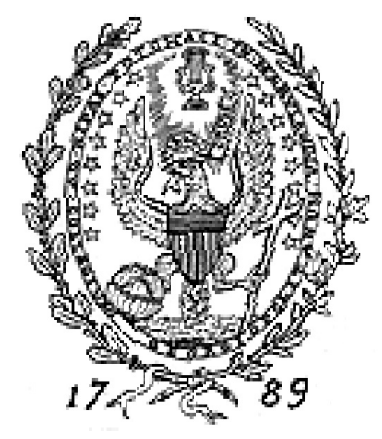

Bioethics Research Library

The Joseph and Rose Kennedy Institute of Ethics

Box 571212, Georgetown University

Washington, DC 20057-1212

202-687-3885; fax: 202-687-8089

bioethics@georgetown.edu

http://bioethics.georgetown.edu

\title{
Gender Issues in Health Care
}

\author{
Pat Milmoe McCarrick \\ Revised March, 1995
}

In the 1990s, many questions are being asked about differences between the treatment of women and men in the health care setting and about the omission or underrepresentation of women in clinical research. Such questions about the quality of care received by women, including those in elderly and ethnic populations, have generated not only a general interest in change, but also new federal mandates. There is an increasing awareness of the need to initiate studies to identify differences in health care, to recognize and assess disease symptoms, to improve diagnosis and prognosis, and to increase knowledge of the definition of a healthy life for those groups who have been largely ignored in past decades.

Interest in women as persons whose normal health status was different from that of men, first received public attention in the early 1970s. A popular book, OUR BODIES, OURSELVES: A BOOK BY AND FOR WOMEN, which appeared in 1973, offered practical suggestions for women's health and raised questions about and provided suggestions for ways in which women could gain better health and more control over their medical treatment (V, Boston Women's Health Book Collective 1973). Since then many books have been published about how women's bodies have been perceived and treated by society and the health care system. These books continue to stimulate interest in the ways the attitudes and practices of researchers and health professionals affect the care of women, pointing out gender differences and raising ethical questions of justice.

An early (1973) pamphlet by Barbara Ehrenreich and Deirdre English, COMPLAINTS AND DISORDERS: THE SEXUAL POLITICS OF SICKNESS, (V, 1973) remarks on the once prevalent use of science to justify the description of normal female body functions as illnesses or indications for medical treatment, which created an atmosphere in which women's experience was seen as abnormal. FOR HER OWN GOOD: 150 YEARS OF THE EXPERTS' ADVICE TO WOMEN (V, Ehrenreich and English 1978) expands on this work, providing more examples of the medicalization of female functions.

The 1985 WOMEN'S HEALTH: REPORT OF THE PUBLIC HEALTH SERVICE TASK FORCE ON WOMEN'S HEALTH ISSUES determined that a condition constitutes a women's issue if the disease or condition is unique to women, more prevalent in women, or more serious among women, and/or if it presents different risk factors for women or requires different interventions for women (V, United States Public Health Service 1985). 
The Council on Ethical and Judicial Affairs of the American Medical Association urges physicians both to examine their practices to be sure that gender is not used as a consideration in their decision making and to suggest further research to determine the extent to which physician-patient relations may be influenced by cultural and social conceptions of gender (II, American Medical Association, 1991).

In a 1990 New York Times essay, the president of a group of health maintenance organizations stated that the New York City Department of Health had a one-year backlog of 2,000 unanalyzed Pap tests. Asserting that the women who relied on the city's services were thus endangered by possible cervical cancer that could be treatable, he stated that something is "deeply wrong" when women die from diseases that are treatable or succumb to diseases that further research might prevent (V, Abramson 1990).

Women's health issues also arise in the area of human rights. For example, female circumcision, which is condemned by the World Health Organization, but widely practiced in many parts of the world, is identified as a women's health issue in recent literature. Questions of cultural relativism are raised, but international principles of human rights are offered as the reason to respect the young females involved (IV, James 1994).

\section{RESEARCH ON WOMEN}

For many years, men have been the usual participants in health care research, with the result that findings in normal men became the standard for all populations. The ways in which men reacted to treatments and to drugs became the only information available and were applied to all populations. The reasons given for the exclusion of women from clinical trials ranged from the rationale that women could become pregnant and, therefore, were not suitable subjects, to the absence of a women's rest room at the study facility. The latter reason was used to justify the exclusion of women from a study on aging conducted in Baltimore, even though many more women than men live long enough to suffer the problems of age. Dr. Robert Butler, former director of the National Institute of Aging, said that the problems of age are "the problems of women." (III, Nechas and Foley 1994).

Ruth Macklin holds that with the exception of reproductive research, the "preponderance of biomedical research carried out in the modern era has ignored women" with its disproportionate use of male subjects. She says this violates the ethical principle of justice which "embodies the obligation to treat like case alike" (IV, Macklin 1993). Rebecca Dresser calls the past research concentrating on men "a glaring moral mistake." She writes that "particular biological characteristics of women and members of nonwhite racial and ethnic groups must not be viewed through the narrow prism of the status quo, which too frequently labels "difference" as a "problem” (IV, Dresser 1992).

The National Commission for the Protection of Human Subjects of Biomedical and Behavioral Research developed subject research guidelines in 1975 which were incorporated into federal regulations for research on human subjects. Pregnant women were selected as one of the groups for whom research was limited. In 1977 the Food and Drug Administration issued General Considerations for the Clinical Evaluation of Drugs, which advised excluding all women of childbearing age from drug trials (IV, Taylor 1994).

The National Institutes of Health (NIH) Office of Research on Women's Health was established in 1990 along with the Women's Health Initiative, a $\$ 625$ million study to see that women participate fully and appropriately in clinical research, including clinical trials, with an emphasis on the later years of life. Although women live about seven years longer than men, their physical, disabilities place many of them in nursing homes for these final years, according to Dr. Vivian Pinn, director of the Women's Health Office at the NIH (V, Herman 1992). Bernadine Healy, who was Director of the NIH at the time the new women's office was established, urged a "general awakening" to the unique medical problems of women (IV, Healy [second citation] 1991). In an interesting contrast, Andrew Kadar maintains that gender bias is a myth and that women receive more and better medical care, resulting in their greater longevity (IV, 1994). 
In 1992, NIH placed coronary heart disease on the research agenda in an attempt to expand the information obtained during the years when only white males were studied. Heart disease is the major killer of both men and women: within one year of suffering a heart attack, half of the women will die; in contrast, "only" 31 percent of men with heart attacks will die within a year. Usually heart disease in women is diagnosed at a more advanced stage than in men, and the new studies will look at the disparities between the symptoms and care of women and men (V, Herman 1992).

The primary use of white males in research studying coronary heart disease may have ramifications beyond the lack of data on women and other ethnic groups, according to Kay-Tee Khaw. Budget constraints and the use only of proven therapies may bring pressure on care givers "to exclude population groups who have not been studied from access to particular interventions because of lack of proved benefit" (IV, Khaw 1993).

Women also have been underrepresented in research on the use and effect of pharmaceutical drugs, even though women receive 60 to 70 percent of all prescriptions. The drugs prescribed generally were tested only on men, and the adverse reactions for women were unknown (II, American College of Clinical Pharmacy 1993). The American Medical Association also noted gender disparities in renal dialysis studies, lung cancer diagnosis, and coronary bypass surgery (II, American Medical Association 1991).

At a hearing of the U.S. House of Representatives Select Committee on Aging's Subcommittee on Housing and Consumer Interests, Chairman Marilyn Lloyd concluded her opening statement by saying: "It's very clear that the lack of implementation of NIH policies affecting women's health research has caused great pain, suffering, and the losses of women's lives." (I, United States. Congress. House, 1991).

There are many different gender issues involved in health care. This Scope Note provides a broad overview of the ways in which the health care and bioethical literature have reported and looked at gender issues, although emphasis is placed on the quality of medical treatment and biomedical research. It does not encompass the literature on caring or the ethics of care, nor does it address the large body of feminist theory and philosophical literature on ethics and medicine.

\section{GOVERNMENT}

Australia. National Health and Medical Research Council (NHMRC). A WOMEN'S HEALTH STRATEGY AND IMPLEMENTATION PLAN. Canberra: Australian Government Publishing Service, 1994. 26 p.

The NHMRC's goal is to ensure an equitable approach to the use of health care resources by women. The Council will implement policy to identify specific health problems of concern to women and to provide adequate access and acceptable service and outcomes in health care delivery and health system processes.

Baine, David P. VA HEALTH CARE FOR WOMEN: DESPITE PROGRESS, IMPROVEMENTS NEEDED. [Testimony before U.S. Senate Committee on Veteran's Affairs, July 2, 1992.] Washington: General Accounting Office, 1992. 7 p. [GAO/T-HRD-92-33].

The director of the Veterans Administration Office of Federal Health Care Delivery Issues testified that physical examinations, including cancer screening, for women veterans were sporadic, VA medical centers were not adequately monitoring mammography programs, and privacy issues affecting women patients needed identification and correction.

Nadel, Mark V. NATIONAL INSTITUTES OF HEALTH: PROBLEMS IN IMPLEMENTING POLICY ON WOMEN IN STUDY POPULATIONS. [Statement before the Subcommittee on Health and the Environment, Committee on Energy and Commerce, U.S. House of Representatives, 18 June 1990]. Washington: U.S. Government Accounting Office, 18 June 1990. 13 p. [GAO/T-HRD-90-38].

Nadel states that NIH made little progress in implementing its policy to encourage the inclusion of women in research study populations following an October 1986 announcement that it would do so. He cites the Division of Research Grants as instructing "reviewers not to consider the inclusion of 
women as a factor of scientific merit in the initial evaluation of grant applications" even though the original policy announcement encouraged researchers to analyze study results by gender.

United States. Congress. House. Select Committee on Aging. Subcommittee on Housing and Consumer Interests. Hearing. WOMEN HEALTH CARE CONSUMERS : SHORT-CHANGED ON MEDICAL RESEARCH AND TREATMENT. July 24, 1990. Washington: U.S. Government Printing Office, 1991. $174 \mathrm{p}$.

Various persons testified at the hearing that women were virtually nonexistent in many large epidemiological studies, including those about aspirin and heart disease, breathlessness as a possible symptom of early heart disease, type A behavior and heart disease, alcohol or smoking and heart disease, and other large-scale studies.

United States. Public Health Service. Office on Women's Health. ACTION PLAN FOR WOMEN'S HEALTH. Washington: U.S. Department of Health and Human Services, Public Health Service, 1991. 165 p.

Reaffirming the status of women's health as a national public health priority, the Public Health Service states the goals of its different branches to ensure adequate and appropriate research on major issues; to improve access to care; to offer health education, particularly in preventive care; and to enhance communication and awareness, in the training of health care professionals and among patients and public.

\section{ASSOCIATIONS}

American College of Clinical Pharmacy. Women as Research Subjects. ACCP White Paper. Pharmacotherapy 13(5): 534-542, September-October 1993.

Noting that drugs are prescribed for women more frequently than for men, the paper says that little information exists about the "pharmacokinetics, pharmacodynamics, and adverse reactions in women for most agents," since women have been "excluded from most randomized, controlled, clinical trials and major epidemiologic studies." Three recommendations to address gender issues are: to design research protocols that consider social factors that may affect response to drug therapy and the health status of women; to include women of various racial, ethnic, and socioeconomic groups; and to develop studies that look at women's health over the life cycle.

American Medical Association, Council on Ethical and Judicial Affairs. Gender Disparities in Clinical Decision Making. Journal of the American Medical Association 266(4): 559-562, 24/31 July 1991.

Declaring concerns that women were at a disadvantage due to inadequate attention to the research, diagnosis, and treatment of their health problems, the Council on Ethical and Judicial Affairs looked at studies that indicated disparities in renal dialysis, lung cancer diagnosis, and coronary bypass surgery. Although women generally receive more health services than men, the Council says that perceiving men's use of these services as 'normal' and women's as 'overanxious' may do a disservice to both sexes.

\section{BOOKS}

Apple, Rima D., ed. WOMEN, HEALTH, AND MEDICINE IN AMERICA: A HISTORICAL HANDBOOK. New York: Garland Publishing, $1990.580 \mathrm{p}$.

Women, Health, and Medicine in America notes that "the only way to demonstrate that women are special is to compare them to men, and vice versa. Studying just women leads to thinner empirical and less steady theoretical results. This comparative stance is a standard one in sociology ... [it] says as much about men as women."

Bair, Barbara; and Cayleff, Susan E., eds. WINGS OF GAUZE: WOMEN OF COLOR AND THE EXPERIENCE OF HEALTH AND ILLNESS. Detroit: Wayne State University Press, $1993.393 \mathrm{p}$.

Alternative health care from different cultural experiences is described by writers who say that conventional Western medicine has denied access and deprived non-white, women patients of their traditional health beliefs. The authors hold that the definition of health and well-being for women from Asian, African, and Latin 
backgrounds may be different from whitedefined norms.

Fausto-Sterling, Anne. MYTHS OF GENDER: BIOLOGICAL THEORIES ABOUT WOMEN AND MEN. New York: Basic Books, 1985. $258 \mathrm{p}$.

The biologist author explores what she calls commonly held myths about men and women, analyzing biological, genetic, evolutionary, and psychological health theories, and concludes that many stereotypes are worthless. "In the study of gender (like sexuality and race) it is inherently impossible for any individual to do unbiased research." She urges researchers to state where they stand and not to pretend objectivity.

Fisher, Sue. IN THE PATIENT'S BEST INTEREST: WOMEN AND THE POLITICS OF MEDICAL DECISIONS. New Brunswick, NJ: Rutgers University Press, 1986. 214 p.

Fisher looks at the doctor-patient relationship, saying that the physician's institutionally-based authority shapes the delivery of care and the language of the dialogue. She concludes that women patients are often treated when it may be medically unnecessary, and she urges women to become more involved in decision making about care.

Jacobus, Mary; Keller, Evelyn Fox; and Shuttleworth, Sally, eds. BODY/POLITICS: WOMEN AND THE DISCOURSES OF SCIENCE. New York: Routledge, 1990. 197 p.

The chapters in this book point out that many controversies in modern science have the female body at their core.

Koblinsky, Marge; Timyan, Judith; and Gay, Jill, eds. THE HEALTH OF WOMEN: A GLOBAL PERSPECTIVE. Boulder, CO: Westview Press, 1993. 290 p.

Reporting on the 1991 National Council for International Health's Conference on "Women's Health: The Action Agenda," the editors note a lack of access to health care in much of the world. They say that gender-specific data is needed to insure that resources are equitably shared, that gender discrimination should be confronted, and that women themselves should determine their needs and risks. Chapters include discussions of mental health, access to care, and quality of care.

Mahowald, Mary Briody. WOMEN AND CHILDREN IN HEALTH CARE: AN UNEQUAL MAJORITY. New York: Oxford University Press, 1993. 281 p.

Mahowald examines the discrepancy between the study of women and children's health care and the concept of equality among human beings, commenting on gender stereotypes that she says the health care system reflects. She points out that normal, healthy women involve themselves in the health care system in connection with childbirth, or on behalf of their children, but that normal, healthy men do not have this experience, thus women have greater involvement in the system.

Mastroianni, Anna C.; Faden, Ruth; and Federman, Daniel, eds. WOMEN AND HEALTH RESEARCH: ETHICAL AND LEGAL ISSUES OF INCLUDING WOMEN IN CLINICAL STUDIES. Two volumes. Washington, DC: National Academy Press, 1994. 247 p. and $271 \mathrm{p}$.

Volume One looks at social, ethical, and legal issues concerned with women's participation as subjects in medical research, exploring issues related to ethical justice in clinical studies. It describes the change from very protective attitudes about including women (particularly those of reproductive age) in research studies to more recent views that emphasize access to clinical trials so that women share both the risks and the benefits of such research. Prepared by the Committee on the Ethical and Legal Issues Relating to the Inclusion of Women in Clinical Studies of the Institute of Medicine, Chair Ruth Faden says that the committee wanted to combine ethical, legal, social, and scientific study into guidelines for the full inclusion of women in clinical research, stressing the importance of a thorough, informed consent process. The 25-page Executive Summary at the beginning of the report discusses guiding principles for justice in clinical studies; scientific considerations; social and ethical considerations; legal considerations; risks to reproduction and offspring; and implementation and recommendations for investigators, IRBs (institutional review boards), IRGs (initial 
review groups), TEGs (technical evaluation groups), scientific advisory councils, and the $\mathrm{NIH}$ (National Institutes of Health). The appendices include an annotated bibliography of articles about women's participation in clinical studies between 1977 and 1993, and the NIH Revitalization Act of 1993 Public Law 103-43. Volume Two contains the text of presentations given at an Institute of Medicine workshop that addressed ethical issues related to recruitment, retention, and the inclusion of pregnant women or those of childbearing age in clinical trials; legal issues; and federal regulations.

Muller, Charlotte F. HEALTH CARE AND GENDER. New York: Russell Sage Foundation, 1990. $258 \mathrm{p}$.

Muller considers how gender affects people's ability to receive the health care that they need and notes that biases can be found not only in relationships between patient and doctor, but in the scientific evaluation and diffusion of medical research. She discusses treatment issues, health comparisons by gender, the financing of care, and fertility-related services. She offers health usage statistics, including information about underusage, various health needs of the working population, and prescription drugs for the elderly.

Nechas, Eileen, and Foley, Denise. UNEQUAL TREATMENT: WHAT YOU DON'T KNOW ABOUT HOW WOMEN ARE MISTREATED BY THE MEDICAL COMMUNITY. New

York: Simon and Schuster, 1994. 272 p.

Asserting that women are still not getting the full benefit of medical technology or treatment, the authors write about the neglect of women in research studies, the ongoing view of physicians that the male body and symptoms are "normal," and the disregard for the effect of violence, abuse, and poverty on women. They conclude that women have been ignored because they have been considered less valuable to society than men. The topics discussed include heart disease, breast cancer, AIDS, aging, and maternal-fetal relations.

Offerman-Zuckerberg, Joan, ed. GENDER IN TRANSITION: A NEW FRONTIER. New York: Plenum Medical Book Company, 1989. $310 \mathrm{p}$.
The author looks at gender dynamics in the area of biotechnology, discussing future possibilities and problems.

Pinotti, Jose Aristodemo, and Faundes, Anibal. WOMEN AND THEIR RIGHT TO A HEALTH POLICY. Carnforth, Lancs, U.K.: Parthenon Publishing Group, 1990. 150 p.

Contributors from the State University of Campinas in Sao Paulo, Brazil, express the need for improvement of health service delivery in Latin America, particularly in Brazil. Legislation, technology, women's reproductive health, prostitution, and medical education are among the topics included.

Sherwin, Susan. NO LONGER PATIENT: FEMINIST ETHICS \& HEALTH CARE. Philadelphia: Temple University Press, 1992. $286 \mathrm{p}$.

Sherwin says that some ethical situations in bioethics may be "invisible" unless they are viewed from a feminist viewpoint. She looks at abortion, reproductive technologies, paternalism and research, calling them traditional problems in health care ethics. She criticizes the fact that few discussions show the importance of social status in health and health care, and suggests that bioethics itself is an instrument of gender bias.

Shorter, Edward. WOMEN'S BODIES: A SOCIAL HISTORY OF WOMEN'S ENCOUNTER WITH HEALTH, ILL-HEALTH AND MEDICINE. New Brunswick, NJ: Transaction Publishers, 1991. 398 p.

Shorter proposes that the "misadventures of childbirth, abortion, and various disabling conditions to which men were not vulnerable imposed on women too many limits to permit a concept of personal autonomy."

Smith, John M. WOMEN AND DOCTORS: A PHYSICIAN'S EXPLOSIVE ACCOUNT OF WOMEN'S MEDICAL TREATMENT-AND MISTREATMENT - IN AMERICA TODAY AND WHAT YOU CAN DO ABOUT IT. New York: Atlantic Monthly Press, 1992. 241 p. Smith, an obstetrician-gynecologist, blames physicians for many of the problems that plague the health care system and states that his 
specialties are particularly responsible for such abuses as unnecessary surgery, inappropriate treatment or testing, prejudicial treatment, and sexual abuse. ". . . [W]omen are mistreated on a major scale. They experience these abuses far more frequently than their male counterparts, regardless of economic or work status or any other factor. Gender alone is the determinant."

Todd, Alexandra Dundas. INTIMATE ADVERSARIES: CULTURAL CONFLICT BETWEEN DOCTORS \& WOMEN PATIENTS. Philadelphia: University of Pennsylvania Press, 1989. 167 p.

Todd audiotaped communications between gynecologists and patients over a two-year period, finding problems that she says reflect a skepticism toward medical care and medical research. She notes that a woman seeking reproductive services is not usually ill, but assumes the role of a patient in order to obtain these services. These encounters therefore represent a real difference in perspective from other medical care.

\section{ARTICLES}

Angell, Marcia. Caring for Women's Health-What Is the Problem? Editorial. New England Journal of Medicine 329(4): 271-272, 22 July 1993. Letters. New England Journal of Medicine 329(24): 1816-1817, 9 December 1993. Angell warns that researchers should include women in clinical trials more often, but not "according to a formula that would make clinical trials more difficult than ever and probably be counterproductive in terms of learning about differential effects in women... . The requirements also assume that clinically important differences between men and women are the rule rather than the exception-a biologically implausible assumption." She does not favor a women's health specialty ("it would marginalize the care of women, and leave the mainstream to men, where lack of attention to women's health would then be officially sanctioned"). She urges that women become part of the upper echelon of academic medicine in order to influence the next generation of doctors and researchers, thereby eliminating a need for special rules for women's health. Letters to the journal about this article indicate that the National Cancer Institute's budget allots seven times as much for breast cancer as prostate cancer, exceeding that for lung cancer, which kills three times as many men and women.

Anthes, Susan, and Crowe, Lawson. Women and Medicine: Ethical Issues-A Bibliographical Review of Selected Books 1970-1990. Behavioral \& Social Sciences Librarian 12(2): 1-22, 1993.

The authors offer a selective literature review of books concentrating on ethical problems arising from the medical treatment of women. They identify three problem areas: the failure to recognize the right of the female patient to self-determination; the assumption by many physicians that certain popular male values are uniformly shared by females; and the development of technology that can lead to treating organs and diseases rather than individuals.

Bennett, J. Claude, for the Board on Health Sciences Policy of the Institute of Medicine. Inclusion of Women in Clinical Trials-Policies for Population Subgroups. New England Journal of Medicine 329(4): 288-291, 22 July 1993.

Saying that both women and minority groups have been excluded or underrepresented in many clinical trials, the Board from the Institute of Medicine (IOM) describes a Congressional proposal that all NIH trials must be designed and carried out in a manner that provides a valid analysis for all without consideration to cost. The IOM urges that all research should establish a set of guidelines, collect data on variables, make plausible extrapolations, and use case histories to provide insights. "Determining the number of women to be included in a trial should reflect reasonable hypotheses about the relation of treatment efficacy to sex, not global rules about the composition of study cohorts."

Bickell, Nina A.; Earp, Jo Anne; Garrett, Joanne M.; and Evans, Arthur T. Gynecologists' Sex, Clinical Beliefs, and Hysterectomy Rates. American Journal of Public Health 84(10): 1649-52, October 1994.

A questionnaire sent to all 77 female and 154 randomly selected male gynecologists in North 
Carolina indicated that the males performed 60 percent more hysterectomies than the females. The authors suggest that patients should express their own preferences and "possibly seek the opinion of more recently trained gynecologists."

Bickell, Nina A.; Pieper, Karen S.; Lee, Kerry L.; et al. Referral Patterns for Coronary Artery Disease Treatment: Gender Bias or Good Clinical Judgment? Annals of Internal Medicine 116(10): 791-797, 15 May 1992.

The authors studied 5,795 patients to determine whether gender bias existed in referral for coronary-bypass-graft surgery among patients with catheterization-documented coronary artery disease. When little or no survival benefit between surgery or medical treatment was perceived, women were less likely to be referred for a coronary bypass graft; when patients were more severely diseased and surgery offered better survival benefits, women were as likely as men to be referred for the procedure. Based on surgical survival benefits, the authors conclude that the referral patterns may have been more appropriate for women than for men.

Bowles, E. Elizabeth. The Disfranchisement of Fertile Women in Clinical Trials: The Legal Ramifications of and Solutions for Rectifying the Knowledge Gap. Vanderbilt Law Review 45(4): 877-920, May 1992.

Bowles says that the legal community can encourage the inclusion of women in clinical trials through litigation. She suggests that Congress should be encouraged to pass a Women's Health Equity Act to improve research methodology.

Clancy, Carolyn M., and Massion, Charlea T. American Women's Health Care: A Patchwork Quilt with Gaps. Journal of the American Medical Association 268(14): 1918-1920, 14 October 1992.

The authors describe a gap between actual and optimal primary care for women. They include discussion of the financial barriers to access and the need for examining the content of primary care. They say that historically "women's health care needs have been categorized as 'reproductive' and then 'all other'.'

Clarke, Karen W.; Gray, David; Keating, Nicola
A.; and Hampton, John R. Do Women with Acute Myocardial Infarction Receive the Same Treatment as Men? British Medical Journal 309(6954): 563-566, 3 September 1994.

The authors studied information about all patients, alive or dead, with suspected myocardial infarction brought to the hospitals in Nottingham, England, during selected periods since 1973. Saying that there is good evidence that certain interventions benefit patients with myocardial infarction, the authors found that women took longer than men to arrive at the hospital, were less likely to be admitted to the coronary care unit, were less likely to receive thrombolytic treatment, and were less likely to receive secondary prophylaxis at discharge. They conclude that survival chances both in the hospital and after discharge are reduced for women because they do not have the same opportunity for therapeutic intervention as men.

Cotton, Paul. Examples Abound of Gaps in Medical Knowledge Because of Groups Excluded from Scientific Study. Journal of the American Medical Association 263(8): 1051, 1055, 23 February 1990.

Cotton describes studies of women, AsianAmericans, and African-Americans, and concludes that their specific ethnic and sexual differences produce unique data in drug responses or other health situations.

Cotton, Paul. Women's Health Initiative Leads Way as Research Begins to Fill Gender Gaps. Journal of the American Medical Association 26(4): 469-470, 473, 22/29 January 1992.

Reporting on NIH's Women's Health Initiative, Cotton states that five of NIH's twelve institutes will participate in a ten-year, half-billion dollar study of diet, dietary supplements, exercise, hormone therapy, smoking, cancer, and osteoporosis in 140,000 postmenopausal women. He notes that Trudy Bush, associate professor of epidemiology at Johns Hopkins University, says the study is too complex to work and too large for the sum allotted.

DeBruin, Debra A. Justice and the Inclusion of Women in Clinical Studies: An Argument for Further Reform. Kennedy institute of Ethics Journal 4(2): 117-146, June 1994.

Outlining the various ways in which women 
may be oppressed and in which that oppression is reflected in research, DeBruin suggests ways to remedy the situation: women must be treated autonomously, society must value the lives and well-being of women, researchers should safeguard possible or actual fetuses, studies must carefully plan research on both men and women who are potential parents, and liability laws in research should be consistent with moral views. She argues that justice requires a policy of preferential treatment as a remedy for past unjust practices.

Dresser, Rebecca. Wanted: Single, White Male for Medical Research. Hastings Center Report 22(1): 24-27, January-February 1992.

Enumerating specific research studies on disease or aging in which white males were the only group studied (no women or nonwhite minorities were included), Dresser suggests that the discovery of bias in the selection of "human subjects hints at as yet unrevealed forms of bias in medicine and biomedical research."

Hannaford, Philip C.; Kay, Clifford R.; and Ferry, Susan. Agism as Explanation for Sexism in Provision of Thrombolysis. British Medical Journal 308(6954): 573, 3 September 1994.

Assessing whether thrombolysis in heart disease is provided on a different basis in men and women, the authors say their study of those who were denied the treatment indicated that age rather than gender was a major factor. Many patients were not given this treatment, and the authors urge all staff to review regularly whether eligible patients are receiving this important treatment.

Healy, Bernadine. Women's Health, Public Welfare. Journal of the American Medical Association 266(4): 566-568, 24/31 July 1991.

Writing as director of the National Institutes of Health, Dr. Healy says that women's health services, research, and access to care have "come of age and become a priority medically, socially, and politically."

Healy, Bernadine. The Yentl Syndrome. Editorial. New England Journal of Medicine 325(4): 274-275, 25 July 1991.

Citing two studies that provide evidence of sex bias in the management of coronary heart disease, Healy says that the "Yentl syndrome" (from an Isaac Bashevis Singer short story that describes a woman who must disguise herself as a man to attend school) is at work. The studies indicate that when a woman has severe disease, she is treated "just like a man," but otherwise receives less treatment.

Hoke, Franklin. NIH Women's Health Researchers Rebut Criticisms of Their Study. Scientist 8(2): 1, 9-10, 24 January 1994.

The Institute of Medicine (IOM) has challenged NIH's study, as part of its Women's Health Initiative, of the hypothesis that a low-fat diet will reduce the risk of breast cancer. Walter C. Willett, an epidemiologist at the Harvard School of Public Health who has followed 120,000 participants in a 17 -year study of nurses, with 110,000 younger women being added in 1989, says a relationship between fat intake and breast cancer has not appeared. In reporting on IOM's criticisms of the Women's Health Initiative, Hoke interviews persons who indicate that the criticism is political, not scientific.

\section{Jackson, Graham. Coronary Artery Disease and} Women: Justifies Equal Opportunity Management. Editorial. British Medical Journal 309(6954): 555-556, 3 September 1994.

Commenting on articles about myocardial infarction in an issue of the British Medical Journal, Jackson says sexual bias may explain the discrepancies in the care received by men and women, but that the differences also may reflect other factors such as older patients with more advanced heart disease or with hypertension, diabetes, and cardiac failure. He notes that women may be more difficult to diagnose and manage than men but that the caretakers must rise to the challenge.

James, Stephen A. Reconciling International Human Rights and Cultural Relativism: The Case of Female Circumcision. Bioethics 8(1): 1-26, January 1994.

James describes the various genital operations involved in female circumcision, and holds that these surgeries represent human rights violations. He says that "cultural survival, diversity and flourishing need not be incompatible with upholding international, universal human rights standards." 
Jecker, Nancy S. Age Based Rationing and Women. Journal of the American Medical Association 266(21): 3012-3015, 4 December 1991. Diekema, Douglas, and Jecker, Nancy S. Letter and reply. Journal of the American Medical Association 26(12): 1612-1613, 25 March 1992.

Pointing out that age-based rationing of health care might seem just since all grow old, Jecker holds that rationing compounds past injustices to women by extending them into old age. She thinks that health policies are already skewed and biased and that women may suffer because "health needs vital to them fall prey to neglect or indifference ... we must actively anticipate gender issues related to all health policies and give them an alert and meticulous hearing."

Jevne, Ronna, and Oberle, Kathleen. Enriching Health Care and Health Care Research: A Feminist Perspective. Humane Medicine 9(3): 201-206, July 1993.

The authors assert that traditional research views social and cultural variables as interfering with objectivity; however, they suggest that these variables should be included to incorporate individual experience. They note that more studies have focused on male subjects even though more women than men have chronic conditions.

Jung, Betty. Gender Disparities in Health Care. Letter. Journal of the American Medical Association 266(21): 2984-2985, 4 December 1991.

Jung recommends the study of all gender differences in health care including the gender of the physician or nurse and the patient's view of the gender of the health professional.

Kadar, Andrew G. The Sex-Bias Myth in Medicine. Atlantic Monthly 274(2): 66-70, August 1994.

Physician Kadar thinks that women are favored in the amount of attention devoted to their medical needs since they spend twice as much money on health care as men. He indicates that NIH spends twice as much money on research specific to women, and only women have a section at NIH studying the diseases of their sex.

Kee, F.; Gaffney, B.; Currie, S.; and O’Reilly, D.
Access to Coronary Catheterisation: Fair Shares for All? British Medical Journal 307(6915): 1305-1307, 20 November 1993.

Studying over 24,000 patients discharged from acute care hospitals in Northern Ireland with a diagnosis of ischemic heart disease, the authors found that men's catheterization-angiography rates were five-fold those of women. Further clinical data would be required, they say, before labelling the lower rate for women as evidence of bias, since it may instead reflect a difference in referral rate or in socioeconomic status.

Khaw, Kay-Tee. Where Are the Women in Studies of Coronary Heart Disease?: White Middle Aged Men Are Not Necessarily Representative of All Humankind. Editorial. British Medical Journal 306(6886): 1145-1146, 1 May 1993.

Khaw urges the British to include women in future research (unless a good reason exists for excluding them) in order to achieve improved practice and health outcomes for them. Khaw says that more research on women may not only benefit women, but also may provide further benefits to men.

Kopelman, Loretta M. Female Circumcision/ Genital Mutilation and Ethical Relativism. Second Opinion 20(2): 55-71, October 1994.

About 80 million women already have had parts of their external genitalia removed, and each year another four to five million girls have such surgery, according to Kopelman, who provides cultural background, clinical descriptions, and a critique of moral issues raised by the practice.

Krumholz, Harlan M.; Douglas, Pamela S.; Lauer, Michael S.; and Pasternak, Richard C. Selection of Patients for Coronary Angiography and Coronary Revascularization Early After Myocardial Infarction: Is There Evidence for a Gender Bias? Annals of Internal Medicine 116(10): 785-790, 1 May 1992.

Although women hospitalized for myocardial infarctions had coronary angiography much less frequently than men, the authors' study indicates no evidence of a difference in the rate of this procedure when adjustments are made for age and severity of coronary disease.

Laskey, Warren. Gender Differences in the 
Management of Coronary Artery Disease: Bias or Good Clinical Judgment? Editorial. Annals of Internal Medicine 116(10): 869-871, 15 May 1992.

Asking if diagnostic and therapeutic approaches to the management of patients with coronary artery disease are different for men and women, Laskey looks at four studies and concludes that there is only an imputation of bias when strategies for treatment are viewed in relation to outcome.

Lurie, Nicole; Slater, Jonathan; McGovern, Paul; et al. Preventive Care for Women: Does the Sex of the Physician Matter? New England Journal of Medicine 329(7): 478-482, 12 August 1993.

The authors identified 97,962 claims for mammography and Pap tests in a large Midwestern health plan, linking the use of these tests to the primary physicians' sex and age. Crude rates for Pap smears and mammography were higher for the patients of female physicians than for those of male physicians in most age groups. They concluded that these tests were done more often if women were patients of female physicians, particularly internists or family practitioners; gender differences were less pronounced between male and female obstetricians and gynecologists.

Macklin, Ruth. Women's Health: An Ethical Perspective. Journal of Law, Medicine \& Ethics 21(1): 23-29, Spring 1993.

Macklin discusses the ethical principles of respect for persons, beneficence, and justice, using such examples as violence, psychological abuse, the right to refuse treatment, the right to access, and risk-benefit assessments.

Mark, Daniel B.; Shaw, Linda K.; DeLong, Elizabeth R.; et al. Absence of Sex Bias in the Referral of Patients for Cardiac Catheterization. New England Journal of Medicine 330(16): 1101-1106, 21 April 1994.

The authors studied 280 men and 130 women who were being evaluated with exercise testing for possible coronary artery disease. While women were referred for cardiac catheterization less often, they had a lower rate of positive exercise-test results. Comparing physicians' estimates of outcome, there was no evidence of underestimates in women nor in the probability of any obstructive coronary disease in men and women who underwent catheterization.

Mason, James O. From the Assistant Secretary for Health, US Public Health Service: A National Agenda for Women's Health. Journal of the American Medical Association 267(4): 482, 22/29 January 1992.

Citing various instances in which women's health issues were ignored or postponed, Mason comments on various federal department's efforts to improve women's health.

McBride, Gail. Women's Study in US Criticised by Expert Committee. British Medical Journal 307(6915): 1299, 20 November 1993.

The author reports that the U.S. Congress' concern over the rise of cost in NIH's women's research plan to $\$ 625,000,000$ and its lengthening to 14 years from 10 years, resulted in asking the Institute of Medicine (IOM) to look at the government's women's study. Eleven experts at IOM produced a 78-page report suggesting changes: to shorten the studies by three years, to redesign the studies, and to present the consent process differently. The IOM group suggests that the main hypothesis be changed from looking at diet and cancer to diet and heart disease.

Mendelsohn, Kathleen D.; Nieman, Linda Z.; Isaacs, Krista; et al. Sex and Gender Bias in Anatomy and Physical Diagnosis Text Illustrations. Journal of the American Medical Association 272(16): 1267-1270, 26 October 1994. Looking at 4,060 illustrations identifiable by sex and gender in 12 commonly used textbooks, the authors found that illustrations of women were underrepresented in nonreproductive anatomy. They think that the depiction of males in a majority of the illustrations may perpetuate the image of the male body as the normal or standard model for medical education.

Merkatz, Ruth B.; Temple, Robert; Sobel, Solomon; et al. Women in Clinical Trials: A Change in Food and Drug Administration Policy. New England Journal of Medicine 329(4): 292-296, 22 July 1993.

The Food and Drug Administration (FDA) changed its policies to provide formal guidance to drug developers indicating its interest in the representation of women in clinical trials and to 
allow women of childbearing potential to be included in early clinical trials. The FDA notes that to exclude these women implies a lack of respect for their autonomy and decision-making capacity.

Miles, Stephen H., and August, Allison. Courts, Gender, and the "Right to Die". Law, Medicine $\&$ Health Care 18(1 \& 2): 85-95, Spring-Summer 1990.

In a study of court decisions about the right to refuse life-sustaining treatment, the authors examined the words and concepts used by the courts in writing final opinions about women or men patients and found "gender patterned reasoning belies a premise of a universal, purportedly gender-neutral, right to refuse treatment." After reviewing 22 decisions from 14 states concerned with surrogate decision making, Miles and August conclude that gender profoundly affects judicial analysis, with women being disadvantaged in "having their moral agency taken less seriously than that of men when a controversial medical decision is evaluated by a court."

Nadelson, Carol D. Ethics, Empathy and Gender in Health Care. American Journal of Psychiatry 150(9): 1309-1314, September 1993.

Nadelson thinks that issues of gender focus and exemplify some concerns about ethical practice in the use of technologic advances in an era of economic concern. She says that more women than men are uninsured or underinsured and thus may be more adversely affected in health policy change. "Disparities in research, practice and the availability of clinical data raise ethical concerns, especially about justice and fairness in determination of policy and in use of resources."

Parker, Lisa S. Social Justice, Federal Paternalism, and Feminism: Breast Implants in the Cultural Context of Female Beauty. Kennedy Institute of Ethics Journal 3(1): 57-66, March 1993.

The author accuses the Food and Drug Administration of unnecessary paternalism when the government agency announced in April 1992 that it would allow all candidates for breast reconstruction to receive silicone breast implants, but offered only limited access for those seeking breast augmentation. She says the job of the regulator is to ascertain a product's safety for all women, allowing the patient to weigh the risks and benefits.

Pearson, Marjorie L.; Kahn, Katherine L.; Harrison, Ellen R.; et al. Differences in Quality of Care for Hospitalized Elderly Men and Women. Journal of the American Medical Association 268(14): 1883-1889, 14 October 1992.

In a study analyzing whether gender differences exist in the quality of hospital care provided to patients with four medical conditions (congestive heart failure, acute myocardial infarction, pneumonia, and cerebrovascular accident), 5,354 men and 5,888 women over 65 years of age were studied in acute care hospitals in 5 states. The study found more similarities than differences in the in-hospital care of elderly men and women. "The concern that gender bias enters into clinical decision making for hospitalized patients is eased in the case of these four diseases, although not entirely eliminated." They nonetheless question why any differences in care exist.

Petticrew, Mark; McKee, Martin; and Jones, Jeremy. Coronary Artery Surgery: Are Women Discriminated Against? British Medical Journal 306(6886): 1164-1166, 1 May 1993.

The authors examined the records of more than 23,000 patients with coronary heart disease discharged from hospitals in the United Kingdom. They found that in all age groups, men were significantly more likely than women to have angiography or coronary artery bypass surgery. The reasons for the greater access to surgery by men than women are uncertain.

Shaw, Leslee J.; Miller, D. Douglas; Romeis, James C.; et al. Gender Differences in the Non-invasive Evaluation and Management of Patients with Suspected Coronary Artery Disease. Annals of Internal Medicine 120(7): 559-566, 1 April 1994.

In a retrospective cohort study of 3,975 middle-aged patients referred for stress testing, the authors determined that women with suspected coronary artery disease have fewer additional diagnostic tests than men even though the incidence of typical angina, cardiac risk factors, and initial diagnostic test positivity rates are similar. 
Stainsby, Mary. Women's Health Issues. St. Vincent's Bioethics Centre Newsletter 10(4): 1-6, December 1992.

"Women's health issues have tended in the past to be regarded as 'the same as men's only different' with the accent being on the sameness and the differences being associated with the health of women in relation to child-bearing." In Australia in 1988-89, the Australian National Health and Medical Research Council's Medical Research Committee distributed $\$ 89.15$ million in research funds with only 1.8 percent given to women and health research. Stainsby lists five criteria of distinct relevance to women or some sub-group of women. She includes and provides examples of conditions, diseases, or problems that are unique to women, more prevalent in women, or more serious among women, as well as those with different risk factors or different interventions for women.

Stauning, Inger. Women, Health, and Medical Technology. International Journal of Technology Assessment in Health Care 10(2): 273-281, Spring 1994.

Stauning discusses the market forces that drive the development of new medical technologies and comments on the lack of evaluation or assessment of risks, benefits, or costs. She urges women at least to be interested in technological developments since much technology has been focused in the area of pregnancy and labor. She cites electronic fetal monitoring and ultrasound scanning as examples of technology that are in routine use and can be valuable in certain situations, but ought not be utilized for all pregnant women, since they may be harmful under normal circumstances.

Taylor, Carol. Gender Equity in Research. Journal of Women's Health 3(3): 143-153, June 1994.

Taylor provides a full and useful historical background to the causes that kept women from being research subjects and the various efforts in the past ten years to achieve gender equity in clinical research. She urges researchers to counsel women fully on the benefits and risks as they enter clinical trials, and makes recommendations concerning recruitment, retention, and changed attitudes to "ensure that guidelines promoting gender equity in research and research practices secure the desired women's health outcomes."

Trafford, Abigail. Gender Bias in Health Care Is No Myth: Discrimination Against Women Occurs in Research and Treatment. Washington Post Health 7(31): 4, 30 July 1991.

Trafford writes "the growing suspicion is that women with the same or worse symptoms are not taken as seriously as men by the medical profession." She thinks elderly women might become stronger and less frail "if doctors treated their symptoms with the same aggressiveness awarded to men." Noting that a survey of women executives found them to be in better health than expected, Trafford says the "key to good health is not gender but status. One reason older women don't fare as well as older men is because they generally have less social and economic clout in their earlier years."

Turney, Lyn. Risk and Contraception: What Women Are Not Told About Tubal Ligation. Women's Studies International Forum 16(5): 471-486, 1993.

Turney reviews literature about tubal ligations and finds there are many possible hazards and complications although the procedure is now the world's most common method of controlling fertility. She questions whether women are informed of the potential for chronic pain or ill health from the ligation or are offered any alternatives to sterilization.

Turshen, Meredeth. The Impact of Sexism on Women's Health and Health Care. Journal of Public Health Policy 14(2): 164-173, 1993.

The author comments on sexism in medical school education as well as gender bias in women's health treatment and research. She cites various life-threatening disparities when men receive tests or studies not given to women. Turshen urges health care institutions to have a clear policy on discrimination against women and the will to enforce the policy.

Vera, Yolanda. Health Care Reform and Women. Clearinghouse Review 28(5): 525-531, August-September 1994.

The author raises questions about health care reform, writing that unaffordable health care disproportionately harms women as they 
generally are poorer than men regardless of age, race, ethnicity, education, or employment status.

Wenger, Nanette K.; Speroff, Leon; and Packard, Barbara. Cardiovascular Health and Disease in Women. New England Journal of Medicine 329(4): 247-256, 22 July 1993.

The authors state there is increasing evidence that women undergo intensive or invasive evaluations and treatments for cardiac disease substantially less often than men with similar or lesser symptoms, even though half-a-million women die annually from cardiovascular illness. They recommend education for both patients and physicians, as well as research that focuses on aspects of cardiovascular disease unique to women or areas where comparisons between men and women are needed.

Wertz, Dorothy C. Provider Biases and Choices: The Role of Gender. Clinical Obstetrics and Gynecology 36(3): 521-531, September 1993.

Wertz looks at gender issues from the view of the physician or the geneticist, finding that female physicians practice medicine similarly to male physicians. She thinks that as the proportion of women in medical practice rises, their influence will rise, but that it remains difficult to gain key posts.

Wilkinson, Paul; Parsons, Luise; and Timmis, Adam D. Acute Myocardial Infarction in Women: Survival Analysis in First Six Months. British Medical Journal 309(6954): 566-569, 3 September 1994.

Studying 216 women and 607 men with acute myocardial infarction, the authors state that women have a worse prognosis than men with excess risk in the first 30 days. They say that the "tendency for women to receive less vigorous treatment than men must be remedied before gender can be considered to be an independent determinant of risk."

\section{REFERENCES/ADDITIONAL READINGS}

Abramson, Leonard. Uncaring Women's Health Care. New York Times, p. A17, 14 May 1990.
Boston Women's Health Book Collective. OUR BODIES, OURSELVES: A BOOK BY AND FOR WOMEN. New York: Simon and Schuster, 1973. $276 \mathrm{p}$.

Corea, Gena. THE HIDDEN MALPRACTICE: HOW AMERICAN MEDICINE TREATS WOMEN AS PATIENTS AND PROFESSIONALS. New York: William Morrow and Co., 1977. 309 p.

Ehrenreich, Barbara, and English, Deirdre. COMPLAINTS AND DISORDERS: THE SEXUAL POLITICS OF SICKNESS. Glass Mountain Pamphlet No. 2. New York: Feminist Press, 1973. 94 p.

Ehrenreich, Barbara, and English, Deirdre. FOR HER OWN GOOD: 150 YEARS OF THE EXPERTS' ADVICE TO WOMEN. New York: Doubleday, 1978. 369 p.

Herman, Robin. What Doctors Don't Know About Women: NIH Tries to Close the Gender Gap in Research. A Special Report. Washington Post Health 8(50): 10-16, 8 December 1992.

Kirschstein, Ruth L. Research on Women's Health. American Journal of Public Health 81(3): 291-293, March 1991.

United States. General Accounting Office. Human Resources Division. WOMEN'S HEALTH: FDA NEEDS TO ENSURE MORE STUDY OF GENDER DIFFERENCES IN PRESCRIPTION DRUG TESTING: REPORT TO CONGRESSIONAL REQUESTERS. Washington: General Accounting Office, [Human Resources Division, P0 Box 6015, Gaithersburg, MD 20884-6015] 1992. 39 p.

United States. Public Health Service. Task Force on Women's Health. Women's Health: Report of the Public Health Service Task Force on Women's Health Issues. Public Health Reports 100(1): 73-106, January-February 1985.

This Scope Note was prepared by Pat Milmoe McCarrick, M.L.S., a reference librarian at the National Reference Center for Bioethics Literature. 